Swarthmore College

Works

Fall 2018

\title{
Lesson Plan For Teaching F. Scott Fitzgerald's "An Alcoholic Case"
}

Samantha Martin , '21

Peter Schmidt

Swarthmore College, pschmid1@swarthmore.edu

Follow this and additional works at: https://works.swarthmore.edu/fac-english-lit

Part of the English Language and Literature Commons

Let us know how access to these works benefits you

\section{Recommended Citation}

Samantha Martin , '21 and Peter Schmidt. (2018). "Lesson Plan For Teaching F. Scott Fitzgerald's "An Alcoholic Case'"'. English Literature Faculty Works. DOI: 10.24968/2476-2458.engl.350

https://works.swarthmore.edu/fac-english-lit/350

\section{(c) (1) (9)}

This work is licensed under a Creative Commons Attribution-Noncommercial 4.0 License This work is brought to you for free by Swarthmore College Libraries' Works. It has been accepted for inclusion in English Literature Faculty Works by an authorized administrator of Works. For more information, please contact myworks@swarthmore.edu. 


\title{
"An Alcoholic Case" by F. Scott Fitzgerald Lesson Plan
}

\author{
English 071D Final Assignment \\ for Professor Peter Schmidt:
}

by

\author{
Samantha Martin \\ Swarthmore College \\ February 10, 2019
}

Details and Pre-class Assignments: The following lesson plan is designed for students of the college and university level during two 1 hour and 15-minute class periods or one 3-hour class period. However, if abbreviated, this lesson plan could focus more in depth on certain aspects of the story and only span one class period.

Students should come to class having read "An Alcoholic Case"1 and the following article by George Monteiro: https://muse.jhu.edu/article/376537/summary. Students should be encouraged to take notes on any additional biographical information they may find as they see it relates to the story, as this will be useful for class discussion.

\footnotetext{
${ }^{1}$ All page numbers from quotes of "An Alcoholic Case" come from the Joyce Carol Oates Oxford Book of American Short Stories, second edition.
} 
Learning Goals:

"An Alcoholic Case" raises different concerns regarding topics such as gender roles and addiction. By the end of the lesson students should be able to...

1. Contextualize these concerns within different time periods (namely, the early-mid $20^{\text {th }}$ century and current day) and discuss any changes or consistencies to the relevant cultures that have perhaps led to such trends.

2. Discuss how story elements such as different characterizations, dialogue, and narration contribute to the overall effect of the story and a better understanding of these topics.

3. Identify different reasons an author might have for choosing and specific narrative style and apply a similar style to their own writing.

Discussion Questions ( 45 minutes to an hour):

The professor is encouraged to ask some if not all of the following questions to the class in order to facilitate a discussion and work towards the learning goals.

- The story opens in what seems to be the middle of a conversation (though initially onesided). How does the opening passage of dialogue provide backstory? Do you think this is more or less effective than a narrator's description of these opening events?

\section{Supporting Quotation:}

" 'Let-go — that —oh-h-h! Please, now, will you. Don't start drinking again! Come on — give me that bottle. I told you I'd stay awake givin it to you. Come on. If you don't like that away - then what are you goin to be like when you go home. Come on-leave it with me-I'll leave half in the bottle. Pul-lease. You know what Dr. Carter says-I'll stay awake and give it to you, I'm too tired to be fightin you all night... All right, drink your fool self to death"' (327).

\section{Follow-up Questions:}

○ Were you at all tricked by this passage into at first believing the story was being told through the first person? Does this delay in revealing the close third person narration affect the reader's relationship with the character of the nurse?

- What does the fragmented - yet mostly correct English — dialogue in the opening passage say about the speaker (the nurse)? Does it allude or connect to anything else in the story? [*Professor can bring up how this may connect to broken glass (the bottle and the bus windows) that riddles the story.]

Supporting Quotations Mentioning Broken Glass:

"'Once more you try to get it I'll throw it down,' she said quickly. 'I will - on the tiles in the bathroom.'

'Then I'll step on the broken glass-or you'll step on it.'

'Then let go- oh you promised-'

Suddenly she dropped it like a torpedo, sliding underneath her hand and slithering with a flash of red and black and the words: SIR GALAHAD, DISTILLED LOUISVILLE GIN” (327).

"The glass was all collected - as she got out a broom to make sure, she realized that the glass, in its fragments, was less than a window through which they had seen each other for a moment" (329). 
"Some Halloween Jokester had split the side windows of the bus and she shifted back to the Negro section in the rear for fear the glass might fall out. She had her patient's check but no way to cash it at this time of night; there was a quarter and a penny in her purse" (329).

"It was an oddly clear night when she went out, with slanting particles of thin sleet making white of a blue-black sky. The bus was the same that had taken her into town but there seemed to be more windows broken now and the bus driver was irritated and talked about what terrible things he would do if he caught any kids. She knew he was just talking about the annoyance in general, just as she had been thinking about the annoyance of an alcoholic. When she came up to the suite and found him all helpless and distraught she would despise him and be sorry for him" (332).

- What is the role of names in this story? Who gets a name and who gets a label? What do names (or lack thereof) say about the characters, places, and objects, and how they are perceived by larger society?

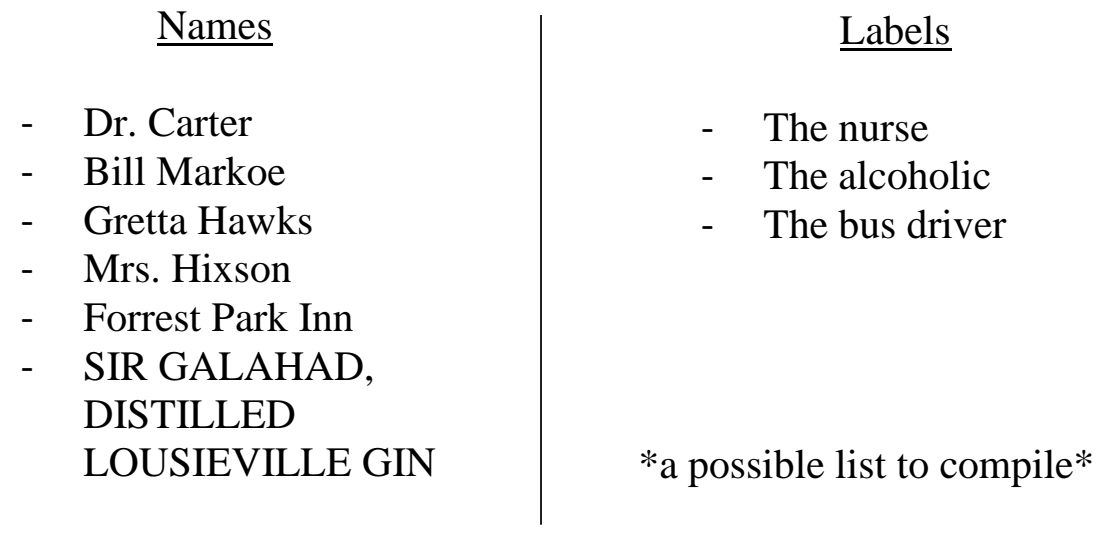

\section{Follow-up Questions:}

$\circ$ Does generalizing the two main characters of the story by not giving them names in any way stereotype them? If not, do you think it does the opposite and instead broadens their experiences to a greater population?

$\circ$ What is the role of Dr. Carter in this story? Why does he get a name when the nurse does not? Does he have agency that the nurse does not? Or vice versa?

\section{Supporting Quotations Mentioning Dr. Carter:}

"Resentfully, she stood up and regarded him. Through the thin, delicate profile of his nose came a light snore, sighing, remote, inconsolable. The doctor had shaken his head in a certain way, and she knew that really it was a case that was beyond her. Besides, on her card at the agency was written, on the advice of her elders, "No Alcoholics"', (329). 
"The phone rang again. 'Oh, hello, Hattie... Well, how about that big Svensen girl? She ought to be able to take care of any alcoholics... How about Josephine Markham? Doesn't she live in your apartment house?... Get her to the phone' then after a moment, 'Jo, would you care to take the case of a well-known cartoonist, or artist, whatever they call themselves, at Forest Park Inn? ... No. I don't know, but Doctor Carter is in charge and will be around about ten o'clock"'(331).

"In the bathroom she saw the pallor and fever on his face and smelled the mixed peppermint and gin on his breath.

'You'll come up soon?' she asked. Dr. Carter's coming at ten.'

'What nonsense! You're coming down with me.'

'Me? She exclaimed. 'In a sweater and skirt? Imagine!'

'Then I won't go.'

'All right then, go to bed. That's where you belong anyhow. Can't you see these people tomorrow?'” (333).

- How do gender roles play into this story? Does the fact that the story was written in the 1930's take away from its application to how addiction and specifically alcoholism are perceived today? Or does this historical context highlight something that has changed or stayed the same overtime on this issue?

\section{Supporting Quotation:}

"She had done her whole duty, but all she could think of was that when she was struggling about the room with him with the gin bottle there had been a pause when he asked her if she had hurt her elbow against a door and that she had answered: 'You don't know how people talk about you, no matter how you think of yourself-' when she knew he had a long time ceased to care about such things" (329).

\section{Follow-up Question:}

○ Refer back to the quote about the broken windows as the nurse returns to the suite in the inn. What do you make of her comparison of these two "annoyances"? Is this fair of her to do? Does the nurse express a common opinion here (see "No Alcoholics" quote above)? If so, has the view of alcoholism and addiction changed in today's culture from one of an "annoyance"? How do these ideas relate to the following scene:

\section{Supporting Quotations:}

"'What kind of case have you been on?'

'Alcoholic,' she said.

'Oh yes - Gretta Hawks told me about it — you were on with that cartoonist who lives at the Forest Park Inn.'

'Yes, I was.'

'I hear he's pretty fresh.'

'He's never done anything to bother me.' She lied. 'You can't treat them as if they were committed-' 
'Oh, don't get bothered-I just heard that around town—oh, you knowthey want you to play around with them-'

'Oh, be quiet,' she said, surprised at her own rising resentment" (330).

- What do you make of the scene when the alcoholic sees his own death in the corner? What is the significance of the few lines succeeding this scene? That is, though this tragedy of death seems to end the story, how do we reconcile there being more said after the alcoholic's death?

- What implications does this scene have concerning the nurse? Does it reveal a shift in her character from the beginning of the story? Can these thoughts be applied more broadly?

\section{Supporting Quotation:}

"Suddenly she knew he wasn't looking for that. He was looking at the corner where she had thrown the bottle this afternoon. She stared at his handsome face, weak and defiant - afraid to turn even half-way because she knew that death was in that corner where he was looking. She knew death — she had heard it, smelt its unmistakable odor, but she had never seen it before it entered into anyone, and she knew this man saw it in the corner of his bathroom: that it was standing there looking at him while he spit from a feeble cough and rubbed the result into the braid of his trousers. It shone there... crackling for a moment as evidence of the last gesture he ever made" (334).

Small Group Discussion ( 25 minutes):

Students will break up into small groups and be presented with the following questions to discuss after searching for specific examples and evidence within the text.

- Does the nurse change at all over the course of the story? Does her perception of the alcoholic change? Does her perspective on alcoholics/alcoholism change in general? How is the reader expected to feel about the nurse? Find specific examples in the text in order to support your argument.

- Does the story call for sympathy for either of these two main characters? To both? How is this done? Consider how literary aspects such as narration and dialogue contribute to your answer. How does point of view specifically contribute to the nurse's connection with the reader? Do you empathize with her? Pity her? Commend her?

- In what ways does the story convey a sense of waste? Consider this question in regards to the nurse, the alcoholic, and broader social issues or institutions. Additionally, how does this story address or fail to address the impact alcoholism or other addictions have on the loved ones of those afflicted? How well does it dramatize how difficult it is to quit addictive behaviors, and the cost and stress of those behaviors on others, including caregivers? [Regarding these questions, teachers are encouraged to make room in class discussion if needed for students to discuss in a safe space addictive behaviors 


\section{and their consequences drawing on their own experiences, perhaps involving friends and family.]}

- Did how the story ended match up with how you thought it might? Did it surprise you? What does an ending like this leave the nurse to conclude or feel about the alcoholic or alcoholism in general? What does it leave the reader to conclude - if in fact any conclusions can be made?

Class Discussion ( $\sim 30$ minutes):

The professor will call everyone's attention back together and each group will have an opportunity to present material and passages they talked through and other students will have an opportunity to make comments on these ideas.

George Monteiro Article Discussion ( 15 minutes):

- How did reading this piece change your perspective on "An Alcoholic Case," if at all? Does looking back on the work having more identity to the alcoholic influence the sympathy you have for him? If so, what does this mean on a larger scale? In terms of how strangers vs family/friends/celebrities are sympathized with? Humanized?

Creative Writing Assignment (Explain assignment in the remaining class time):

Consider how Monteiro describes Fitzgerald's approach to his narrative style in "An Alcoholic Case":

"His solution was to retain the narrative voice but to limit himself to the consciousness of the nurse handling the alcoholic case who was based on himself. That way he could perform the fictional trick of writing about himself as someone else - a woman — would see him, thereby providing a way to distance himself from his autobiographical materials while accruing considerable credibility for the objectivity of his portrait of "an alcoholic case." He would, as it were, exercise that part of his nature he claimed was feminine. In so doing, moreover, he would be able to tell a double story - that of the alcoholic (himself) and that of his nurse (the composite of several nurses who attended him in Baltimore and Asheville)" (112).

Recall a "scene" in your life in which you wish you could have known what another person was thinking and construct a story of this "scene" using the same close third person narration as Fitzgerald used, in which the narrator is limited to the consciousness (the point of view and voice) of someone in the story who is not yourself.

Assignment Guidelines*:

* May be assigned as a graded or non-graded assignment. The teacher may choose to assign this as ungraded work so that students feel more open to writing about a personal topic. In this case, professors may decide to collect only the reflection portion of the assignment for a completion grade. 
- Anywhere from 1-5 pages in length. The point of this assignment is to practice with this writing technique, not to restrict students' stories or force length upon them.

- Due date is up to the teacher, perhaps up to one week of class discussion.

- Fabrication of events is okay if you cannot think of a true memory in which to write on.

- Have fun with this assignment, but keep in mind the reasons Fitzgerald may have chosen this style. Your story does not have to contain an underlying reveal or be written on a topic such as alcoholism, but do be respectful when using "An Alcoholic Case" as inspiration for your writing style.

- After completing your story, write a 1-2-page reflection on this process. You may consider the following questions for your reflection; however, you are free to write your reflection with or without answering them: Were there specific aspects of the Fitzgerald story that motivated your topic or specific parts of your story? Did you find yourself sympathizing with the person whose consciousness your narration was restricted to more so than when the event actually happened? Has this assignment provided you with any additional insight on "An Alcoholic Case" or the writing style in general?

\section{Works Cited}

Fitzgerald, F. Scott. “An Alcoholic Case”. The Oxford Book of American Short Stories, edited

by Joyce Carol Oates. Second Edition. New York: Oxford University Press, 2013, pp. 327-334.

Monteiro, G. (1987). Fitzgerald vs. Fitzgerald: "An Alcoholic Case". Literature and Medicine,6, 110-116. doi:https://doi.org/10.1353/lm.2011.0010

\section{Reflections on Making this Lesson Plan:}

Upon deciding to write a lesson plan for my final assignment, I immediately thought I would pursue a lesson in the context of another discipline. For example, I greatly considered writing a lesson plan on "An Alcoholic Case" in the context of a clinical psychology class. I wanted to focus on how Fitzgerald's story as both character and author influenced the reader's and the other characters' perceptions of alcoholics, leading perhaps to a better understanding of 
addiction as a whole. However, as I began to construct my lesson plan in this context, I realized that I would be doing the story a disservice of sorts by limiting its teaching in this way. The power of the short story, and especially one by F. Scott Fitzgerald, is its capacity to uphold a multiplicity within itself and its teachings. "An Alcoholic Case" can be applied to many different classes and disciplines, and so I chose to provide the framework of this story as a whole, giving educators the ability to adapt it from this form as they see fit in order to apply to their specific classes and students.

Within the lesson plan, I focus on the perception of alcoholics and alcoholism and hope to promote discussion of this topic among students. There is still a stigma against mental illness and addiction, and I believe the narrative, specifically the short story, can be a means of diminishing this stigma because of the relationship the reader can from with characters. To some degree, this stigma attaches itself not just to the patients in trouble, but to the nurses who work with them. I chose to focus part of the lesson plan on this topic for these reasons along with the idea that such conversation is specifically significant due to Fitzgerald's own history of struggling with alcoholism. While searching for more biographical information on Fitzgerald, I came upon the Monteiro article and ultimately decided to assign it as a secondary source for students to read after having read the story. At first, I was tempted to present part of this article to the class towards the end of the lesson instead of assigning it as additional reading. As I reviewed my entire lesson plan, though, it occurred to me that withholding this article from the students to save as a sort of "surprise topic" at the end, would not be as beneficial as allowing it to come up naturally in discussion with the story before focusing on the source as a wrap up of discussion. 
Writing this lesson plan has revealed something that being part of this short stories class has taught me: that the more people with knowledge and experience reading short stories, the greater the discussion and learning from those stories. The process of drafting and reconsidering discussion questions which try to provoke certain thoughts and connections within the minds of others is only part of the question-writing process. The other part is formulating these questions because I genuinely want to hear the answers that others have. Maybe there's something I overlooked or took to mean something else. I appreciate the opportunity to more carefully consider this process and at the same time develop a greater understanding of "An Alcoholic Case" in itself.

—Samantha Martin 